\title{
PENGARUH SUHU DAN KEPADATAN EPHIPPIA YANG BERBEDA TERHADAP PENETASAN EPHIPPIA Daphnia magna
}

\section{THE INFLUENCE OF DEFFERENT TEMPERATURE AND EPHIPPIA DENSITY FOR EPHIPPIA HATCH OF Daphnia magna.}

\author{
Yulian Cindra Eka Pradana, Boedi Setya Rahardja dan Yudi Cahyoko \\ Fakultas Perikanan dan Kelautan Universitas Airlangga \\ Kampus C Mulyorejo - Surabaya, 60115 Telp. 031-5911451
}

\begin{abstract}
Daphnia magna has good nutrition to carry on egg produce and fry of fish cupang, maskoki, oscar, tetra, and also can used for food source of fry and seed. Daphnia magna not only supply from natural environment, cause their growth deppend on fertilizer as food and environment condition. The other side: high population density, limited of food source low temperature and shorter irradiation can produce dorman egg (ephippia). The dorman eeg can use for Daphnia magna stock which way by hatching. The factor that can be influence for ephippia hatch are temperature and density. Based on this fact, a research about influence of different temperature and ephippia density for ephippia hatch of Daphnia magna. The purpose of this research was to know the influence of different temperature and ephippia density for ephippia hatch of Daphnia magna. This research has experimental characteristic and use Factorial Completely Randomized Design with three experiments of temperature (A factor), three experiments of density (B factor) and three times replicated. There are 9 kinds of combination between density and temperature. The parameter which checked in this research is degree of hatch of ephippia Daphnia magna and water quality that is dissolve oxygen rate, $\mathrm{NH} 3$ and of $\mathrm{pH}$ hatch media.

The result of the analysis showed that the temperature and density influence of hatching Daphnia magna ephippia. The best result can be used for hatching Daphnia magna ephippia is temperature at $25^{\circ} \mathrm{C}$ with density 50 ephippia $/ 100 \mathrm{ml}$ giving highest result for the hatch of ephippia Daphnia magna. There are interaction betwen temperature and density for hatching.
\end{abstract}

Key words : temperature, density, ephippia, hatch, Daphnia magna.

\section{Pendahuluan}

Pakan alami Daphnia magna merupakan udang renik yang digunakan sebagai sumber pakan larva dan burayak (Lingga dan Susanto, 2003). Daphnia magna tidak selalu tersedia di alam. Perkembangannya tergantung pada pakan yang tersedia dan kondisi lingkungan. Pada musim pemijahan ikan, Daphnia magna banyak dicari pembudidaya ikan untuk dimanfaatkan sebagai pakan larva (Sayuti, 2003).

Pada kondisi seperti kepadatan populasi yang tinggi, ketersediaan pakan terbatas, suhu rendah dan pendeknya lama penyinaran akan menghasilkan telur dorman (Delbare and Dhert, 2004). Telur dorman disebut ephippia, telur ini merupakan hasil reproduksi Daphnia secara seksual (Pietzark and Slusarczk, 2003). Ephippia dapat diproduksi secara masal untuk memenuhi ketersediaan dan kontinuitas Daphnia magna yang berkurang di alam pada musim penghujan (Djarijah, 1996).
Berdasarkan penelitian (Setyowati, 2007), penetasan ephippia dari Daphnia spp. dipengaruhi oleh beberapa faktor luar, salah satunya adalah suhu. Apabila suhu dikombinasikan lagi dengan kepadatan ephippia yang tepat, kemungkinan akan memberikan keberhasilan penetasan ephippia yang lebih baik.

Berdasarkan permasalahan tersebut, maka perlu dilakukan penelitian kombinasi suhu dan kepadatan ephippia terhadap efektifitas ephippia dari Daphnia magna. Kombinasi antara kedua perlakuan tersebut diharapkan dapat meningkatkan derajad penetasan ephippia Daphnia magna.

Tujuan dari penelitian ini adalah mengetahui pengaruh suhu terhadap penetasan ephippia Daphnia magna dan pengaruh kepadatan ephippia terhadap penetasan ephippia Daphnia magna, serta kombinasi suhu dan kepadatan ephippia terbaik terhadap penetasan ephippia Daphnia magna. 
Manfaat penelitian ini adalah untuk memberikan informasi ilmiah tentang pengaruh suhu dan kepadatan ephippia berbeda terhadap penetasan ephippia Daphnia magna.

\section{Materi dan Metode Penelitian}

Penelitian ini dilaksanakan pada tanggal 2 - 30 Agustus 2008 di Laboratorium Pendidikan Perikanan, Fakultas Kedokteran Hewan, Universitas Airlangga.

Peralatan yang digunakan selama penelitian adalah termometer, termostat, cawan petri, beacker glass $500 \mathrm{ml}$, gelas 200ml, mikroskop, pipet, seser, styrofoam box, aerator dan slang aerator. Alat untuk mengukur kualitas air adalah kertas pH, DO teskit, amonia teskit.

Bahan yang digunakan selama penelitian adalah ephippia Daphnia magna yang diperoleh dari kultur Daphnia magna dengan menggunakan rendaman dedak sebagai media pemeliharaan, air kultur Daphnia magna, kertas saring, object glass dan air dari PDAM yang telah di aerasi.

Rancangan penelitian yang digunakan adalah Rancangan Acak Faktorial (Kusriningrum, 1989). Perlakuan terdiri dari tiga macam perlakuan suhu $25^{\circ} \mathrm{C}, 27^{\circ} \mathrm{C}, 29^{\circ} \mathrm{C}$ (faktor A) dan tiga macam perlakuan kepadatan 25, 50, 75 butir ephippia /100 ml air (faktor B). serta diulang tiga kali ulangan.

Penentuan Suhu dan Kepadatan

Penelitian ini dilakukan delam tempat tertutup tanpa adanya pengaruh cahaya. Kepadatan yang digunakan 25 butir ephippia/100 ml media, 50 butir ephippia/100 $\mathrm{ml}$ media dan 75 butir ephippia/100 ml media. Media tersebut adalah air dari PDAM yang telah di aerasi.

Suhu air yang digunakan adalah 25, 27, $29{ }^{\circ} \mathrm{C}$. Penetasan dilakukan pada gelas berkapasitas $200 \mathrm{ml}$ yang diisi air sebanyak 100 $\mathrm{ml}$. Setelah dilakukan pengacakan pada gelas, masing-masing gelas dimasukkan ke dalam tiga styrofoam box. Styrofoam pertama dengan suhu air $25^{\circ} \mathrm{C}$ berisi air dengan ketinggian $10 \mathrm{~cm}$ dan termostat yang diset pada $25^{\circ} \mathrm{C}$, dan tempat untuk es yang dipasang dengan posisi menggantung. Styrofoam kedua dengan suhu air $27^{\circ} \mathrm{C}$ berisi air dengan ketinggian air $10 \mathrm{~cm}$ dan termostat yang diset pada $27^{\circ} \mathrm{C}$, tempat untuk es yang dipasang dengan posisi menggantung. Styrofoam ketiga dengan suhu air $29^{\circ} \mathrm{C}$ berisi air dengan ketinggian air $10 \mathrm{~cm}$ dan termostat yang diset pada $29^{\circ} \mathrm{C}$, tempat untuk es yang dipasang dengan posisi menggantung. Kemudian gelas berkapasitas $200 \mathrm{ml}$ yang berisi air sebanyak $100 \mathrm{ml}$ diaerasi selama 24 jam dan menunggu suhu stabil. Setelah 24 jam ephippia mulai di masukkan dalam gelas dengan menggunakan pipet. Penghitungan penetasan ephippia dilakukan setiap hari dengan cara menghitung jumlah ephippia yang menetas dengan bantuan kamera.

\section{Koleksi Ephippia Daphnia magna}

Ephippia yang digunakan berasal dari kultur Daphnia magna dengan menggunakan dedak sebagai pakan. Hal ini dilakukan dengan cara Daphnia magna sebanyak 5000 individu dipelihara pada air media dengan volume 10 liter. Pakan yang digunakan adalah rendaman dedak dengan konsentrasi $125 \mathrm{ppm}$. Pakan diberikan satu kali sehari. Pengambilan ephippia dilakukan pada hari mulai terdapatnya ephippia pada bak penelitian. Ephippia yang dihasilkan terletak didasar bak kultur sehingga harus disipon dan diambil menggunakan pipet (Ernawati, 2007).

Pengamatan kualitas ephippia dilakukan dengan cara mengamatinya dengan mikroskop untuk mengetahui viabilitas. Ephippia yang viable ditandai dengan telur yang berwarna hijau gelap dan embro yang didalamnya masih terlihat utuh (Ernawati, 2007). Ephippia Daphnia magna yang diperoleh kemudian disimpan dalam lemari pendingin dengan suhu antara $1-5^{\circ} \mathrm{C}$ selama 15 hari untuk mengakhiri masa dormansi selanjutnya siap untuk ditetaskan (Rojas et al., 2000).

Parameter utama yang diamati dalam penelitian ini adalah derajat penetasan ephippia. Parameter penunjang berupa pengamatan kadar oksigen terlarut, $\mathrm{NH}_{3}$ dan $\mathrm{pH}$ media penetasan.

Data yang diperoleh ditransformasi $(\sqrt{\%}+0,5)$ kemudian diolah menggunakan Anova (Analysis of Variance) untuk mengetahui adanya pengaruh perlakuan yang diberikan. Data yang dihasilkan bila terdapat pengaruh maka akan dilakukan uji lanjutan, yaitu Uji Jarak Berganda Duncan. 
Tabel 1. Rata-rata derajat penetasan ephippia Daphnia magna (\%) hasil kombinasi perlakuan suhu dan kepadatan selama penelitian tujuh hari.

\begin{tabular}{|c|c|c|}
\hline $\begin{array}{c}\text { Suhu } \\
\left({ }^{\circ} \mathrm{C}\right)\end{array}$ & $\begin{array}{c}\text { Kepadatan } \\
\text { (butir ephippia/100ml) }\end{array}$ & $\begin{array}{c}\text { Derajat penetasan } \\
(\%)\end{array}$ \\
\hline $25\left(\mathrm{~A}_{0}\right)$ & $25\left(\mathrm{~B}_{0}\right)$ & $37,33^{\mathrm{b}}$ \\
& $50\left(\mathrm{~B}_{1}\right)$ & $53,39^{\mathrm{a}}$ \\
& $75\left(\mathrm{~B}_{2}\right)$ & $23,89^{\mathrm{c}}$ \\
\hline $27\left(\mathrm{~A}_{1}\right)$ & $25\left(\mathrm{~B}_{0}\right)$ & $26,67^{\mathrm{c}}$ \\
& $50\left(\mathrm{~B}_{1}\right)$ & $16,67^{\mathrm{d}}$ \\
& $75\left(\mathrm{~B}_{2}\right)$ & $11,56^{\mathrm{e}}$ \\
\hline $29\left(\mathrm{~A}_{2}\right)$ & $25\left(\mathrm{~B}_{0}\right)$ & $0^{\mathrm{f}}$ \\
& $50\left(\mathrm{~B}_{1}\right)$ & $0^{\mathrm{f}}$ \\
& $75\left(\mathrm{~B}_{2}\right)$ & $0^{\mathrm{f}}$ \\
\hline
\end{tabular}

Keterangan: Superskrip yang berbeda pada satu kolom menunjukkan perbedaan yang nyata $(\mathrm{p}<0,05)$ superskrip dengan huruf yang sama pada satu kolom menunjukkan tidak ada perbedaan yang nyata antar perlakuan.

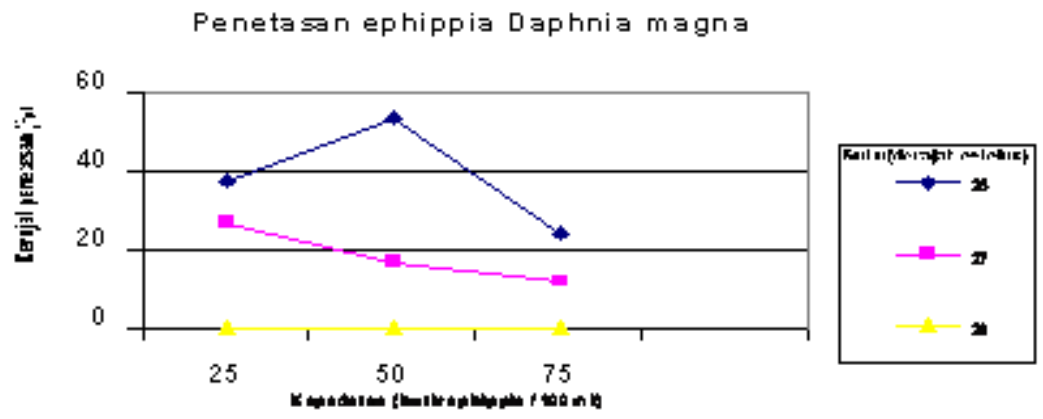

Grafik penetasan ephippia dilakukan selama penelitian dapat dilihat pada Gambar 1 .

\section{Hasil dan Pembahasan}

Hasil penetasan ephippia Daphnia magna dengan perlakuan suhu dan kepadatan selama penelitian tujuh hari. Hasil data derajat penetasan ephippia Daphnia magna selama tujuh hari kemudian ditransformasi $(\sqrt{ } \%+0,5)$. Data transformasi kemudian dianalisis dengan uji statistik. Berdasarkan analisis varian menunjukkan bahwa suhu berpengaruh nyata terhadap penetasan ephippia Daphnia magna $(\mathrm{p}<0,05)$. Sedangkan kepadatan ephippia berpengaruh nyata terhadap penetasan ephippia Daphnia magna serta terdapat interaksi antara suhu dan kepadatan ephippia terhadap derajat penetasan ephippia Daphnia magna ( $<<0,05)$.

Data yang diperoleh selama penelitian

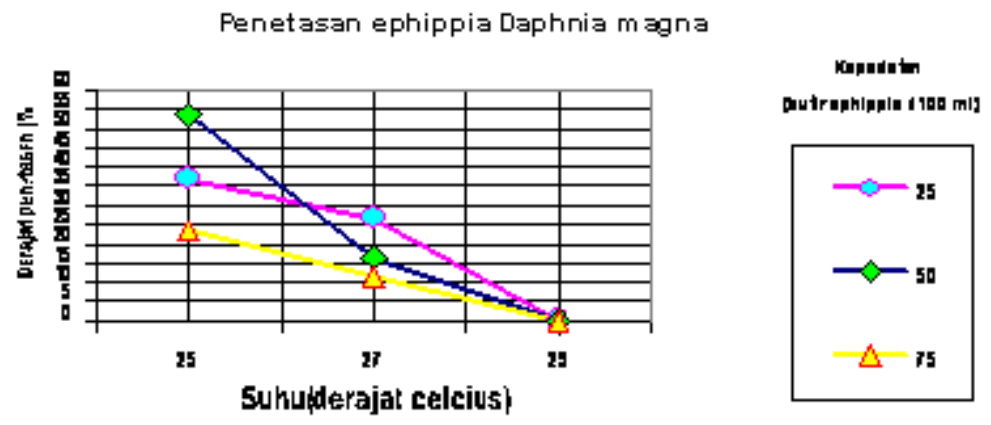

Gambar 1. Grafik derajat penetasan ephippia Daphnia magna pada berbagai suhu dan kepadatan. 
dianalisis secara statistik Data derajat penetasan ephippia Daphnia magna yang ditetaskan pada suhu dan kepadatan ephippia yang berbeda ditampilkan pada Tabel 1.

Pada Tabel 1 perlakuan $\mathrm{A}_{0} \mathrm{~B}_{1}$ merupakan rata-rata derajat penetasan ephippia tertinggi, yang berbeda nyata dengan perlakuan $A_{0} B_{0}$, perlakuan $A_{0} B_{0}$ berbeda nyata dengan perlakuan $\mathrm{A}_{0} \mathrm{~B}_{2}$. Perlakuan $\mathrm{A}_{0} \mathrm{~B}_{2}$ tidak berbeda nyata dengan perlakuan $A_{1} B_{0}$. Perlakuan $A_{1} B_{0}$ berbeda nyata dengan perlakuan $\mathrm{A}_{1} \mathrm{~B}_{1}$ dan berbeda nyata dengan perlakuan $\mathrm{A}_{1} \mathrm{~B}_{2}$, sedangkan perlakuan $\mathrm{A}_{1} \mathrm{~B}_{2}$ berbeda nyata dengan perlakuan $\mathrm{A}_{2} \mathrm{~B}_{0}$. Perlakuan $\mathrm{A}_{2} \mathrm{~B}_{0}$ tidak berbeda nyata dengan perlakuan $\mathrm{A}_{2} \mathrm{~B}_{1}$ dan perlakuan $\mathrm{A}_{2} \mathrm{~B}_{2}$.

Pada Gambar 1 menunjukkan grafik derajat penetasan ephippia Daphnia magna pada berbagai suhu dan kepadatan. Interaksi yang nyata ditunjukkan oleh ketidak sejajaran garis. Secara umum, derajat penetasan ephippia Daphnia magna yang lebih tinggi dicapai pada suhu $25^{\circ} \mathrm{C}$ dengan mengabaikan kepadatan. Perubahan dari suhu $25^{\circ} \mathrm{C}$ ke suhu $27^{\circ} \mathrm{C}$, kepadatan 25, 50 dan 75 butir ephippia/100ml menurun. Suhu $27^{\circ} \mathrm{C}$ ke suhu $29^{\circ} \mathrm{C}$, terjadi penurunan pada semua kepadatan.

Hasil pemeriksaan kualitas air selama penelitian adalah sebagai berikut: nilai rata-rata $\mathrm{pH} 7,3$, sedangkan amoniak $0 \mathrm{mg} / \mathrm{l}$ dan oksigen terlarut $8 \mathrm{ppm}$.

Penyimpanan ephippia pada lemari pendingin pada suhu $0-5^{\circ} \mathrm{C}$ selama 15 hari bertujuan untuk mengakhiri masa dorman ephippia. Ephippia yang telah melalui masa dorman akan peka terhadap perubahan suhu. Salah satu faktor yang mempengaruhi keberhasilan penetasan ephippia adalah suhu (Vandakerkhove, 2005). Barus dan Wahyuningsih (2001) menyatakan kelarutan oksigen dalam air akan semakin menurun seiring dengan meningkatnya suhu perairan. Kombinasi perlakuan antara suhu dan kepadatan ephippia yang tepat dapat menghasilkan efisiensi dalam penetasan ephippia.

Dalam penelitian ini suhu dan kepadatan memiliki pengaruh yang nyata terhadap penetasan ephippia Daphnia magna. Ephippia memiliki kelebihan mudah beradaptasi dengan lingkungan, sehingga ephippia mudah menetas jika berada pada kondisi media yang sesuai untuk menetas (Simson, 2001). Pada uji statistik, data derajat penetasan ephippia Daphnia magna menunjukkan bahwa terdapat pengaruh yang nyata $(\mathrm{p}<0,05)$ pada pelakuan suhu terhadap derajat penetasan ephippia Daphnia magna, terdapat pengaruh yang nyata $(\mathrm{p}<0,05)$ pada pelakuan kepadatan terhadap derajat penetasan ephippia Daphnia magna, serta terdapat interaksi antara suhu dan kepadatan terhadap derajat penetasan ephippia Daphnia magna.

Perlakuan kombinasi suhu $25^{\circ} \mathrm{C}$ dengan kepadatan 25 butir ephippia /100ml menghasilkan derajat penetasan rata-rata sebesar 37,33\%, sedangkan perlakuan kombinasi suhu $25^{\circ} \mathrm{C}$ dengan kepadatan 50 butir ephippia/100ml menghasilkan derajat penetasan rata-rata tertinggi dengan 53,39\%. Penelitian Rojas (2000) menyatakan, suhu $25^{\circ} \mathrm{C}$ serta kepadatan 25 butir ephippia / 50ml menghasilkan derajat penetasan tertinggi pada penetasan ephippia Moina micrura. Perlakuan kombinasi suhu $25^{\circ} \mathrm{C}$ dengan kepadatan 75 butir ephippia/100ml menghasilkan derajat penetasan rata-rata sebesar 23,89\%. Suhu dapat mempengaruhi inkubasi telur, keberhasilan penetasan, lamanya penetasan dan mengakhiri masa dormansi (Ward, 1992). Perlakuan kombinasi suhu $27^{\circ} \mathrm{C}$ dengan kepadatan 25 butir ephippia/100ml menghasilkan derajat penetasan rata-rata sebesar $26,67 \%$, sedangkan perlakuan kombinasi suhu $27^{\circ} \mathrm{C}$ dengan kepadatan 50 butir ephippia/100ml menghasilkan derajat penetasan rata-rata sebesar $16,67 \%$ atau memiliki derajat penetasan yang lebih tinggi dari perlakuan kombinasi suhu $27^{\circ} \mathrm{C}$ dengan kepadatan 75 butir ephippia/100ml yang menghasilkan derajat penetasan rata-rata sebesar $11,56 \%$. Rainkow et al (2005) menyatakan telur dorman merupakan embrio terbuahi yang resistan terhadap kondisi lingkungan yang buruk. Contoh lingkungan yang buruk adalah kepadatan yang tinggi (Delbare and Dhert, 2004). Kepadatan yang tinggi mengakibatkan kondisi stres dan menghasilkan derajat penetasan yang rendah karena berhubungan dengan konsumsi oksigen dan sifat ephippia yang sensitif terhadap lingkungan buruk seperti kepadatan yang tinggi. Jumlah kepadatan sangat berpengaruh dengan konsumsi oksigen yang di butuhkan oleh ephippia untuk membantu proses metabolisme dalam tubuh (Ward, 1992). Kepadatan populasi yang tinggi akan menghasilkan sisa metabolisme yang dapat menurunkan kualitas air, masalah tersebut dapat di atasi dengan aerasi yang cukup (Alkampau, 2007). Perlakuan kombinasi suhu $29^{\circ} \mathrm{C}$ dengan kepadatan 25,50 , 75 butir ephippia/100ml menghasilkan derajat penetasan rata-rata sebesar $0 \%$ karena tidak ada ephippia yang menetas dan sebagian mengalami lisis. Hal tersebut diakibatkan suhu penetasan yang tidak sesuai. Pada suhu diatas suhu penetasan dapat menyebabkan ephippia menjadi lisis (Jusadi, 2003). 
Rata - rata oksigen terlarut stabil pada 8 ppm karena adanya aerasi yang cukup sehingga metabolisme embrio dorman yang berada di dalam ephippia berjalan dengan normal dan mampu mendukung penetasan. Ward (1992) menyatakan oksigen dibutuhkan oleh embrio dorman untuk membantu proses metabolisme yang terjadi di dalam tubuh, sehingga embrio dapat mengakhiri masa dorman dan menetas.

Peningkatan konsentrasi amoniak akan menurunkan nilai $\mathrm{pH}$, sehingga rentang $\mathrm{pH}$ selama kultur menjadi besar (Radini, 2006). Kualitas air pada penelitian ini relatif stabil dengan $\mathrm{pH}$ rata - rata 7,3 dan amoniak rata rata $0 \mathrm{mg} / \mathrm{l}$.

Derajat keasaman pada kisaran 7-8 masih berada pada batas optimum untuk penetasan ephippia. Clare (2004) menyatakan $\mathrm{pH}$ 7,2-8,5 merupakan $\mathrm{pH}$ optimum untuk pertumbuhan Daphnia sp. Setelah menetas dan keluar dari ephippia embrio akan berada pada media penetasan, sehingga $\mathrm{pH}$ pada media penetasan harus sesuai dengan media pemeliharaan Daphnia sp.

\section{Kesimpulan}

Suhu memiliki pengaruh yang nyata pada penetasan ephippia Daphnia magna. Kepadatan memiliki pengaruh yang nyata pada penetasan ephippia Daphnia magna. Terdapat pengaruh yang nyata pada pelakuan suhu dan kepadatan terhadap derajat penetasan ephippia Daphnia magna. Suhu $25^{\circ} \mathrm{C}$ dengan kepadatan 50 butir ephippia/100ml memberikan hasil tertinggi untuk penetasan ephippia Daphnia magna.

Penetasan ephippia dengan suhu $25^{\circ} \mathrm{C}$ dengan kepadatan 50 butir ephippia / $100 \mathrm{ml}$ air memberikan derajat penetasan tertinggi. Penetasan ephippia dipengaruhi oleh banyak faktor, yaitu suhu, intensitas cahaya, oksigen terlarut, salinitas, $\mathrm{pH}$. Oleh karena itu perlu dilakukan penelitian lebih lanjut dengan faktor lain tersebut yang berguna untuk meningkatkan derajat penetasan ephippia.

\section{Daftar Pustaka}

Barus, T. A. dan H. Wahyuningsih. 2006. Hibah Kompetisi Konten Matakuliah ELearning. Buku Ajar Iktiologi. Departemen Biologi. Fakultas Matematika dan Ilmu Pengetahuan Alam. Universitas Sumatra Utara. 119 hal

Clare, J. 2004. Daphnia an Aquaculturerist Guides. http://www.Caudata.org. 3/Januari/ 2008. 13 p.
Delbare, D. and P. Dhert. 2004. Daphnia and Moina. Cladocerans; Nematoda and Trochopora Larvae. www.Fao.org. 3/Maret/2008. 4 p.

Djarijah, AS. 1996. Pakan Ikan Alami. Kanisius. Yogyakarta. hal. 36-39

Ernawati, D. 2007. Hubungan Rasio Induk Jantan Dan Betina Daphnia sp. Terhadap Efisiensi Perkawinan dan Produksi Ephipia. Skripsi. Program Studi S-1 Budidaya Perairan. Fakultas Kedokteran Hewan. Universitas Airlangga. Surabaya. 26 hal.

Jusadi, D. 2003. Budidaya Pakan Alami. http://125.160.17.21. 30/september/2008. hal. 18-19.

Kusriningrum. $1989 . \quad$ Dasar-Dasar Perancanggan Percobaan dan Rancangan Acak Kelompok, Rancangan Bujursangkar Latin, Percobaan Faktorial Universitas Airlangga. Surabaya. hal. 53-104.

Lingga, P dan H. Susanto. 2003. ikan hias air tawar. Penebar swadaya. Jakarta. Hal 17-18.

Radini. D, 2006. Optimasi Suhu, pH Serta Jenis Pakan Pada Kultur Daphnia sp. Sekolah Ilmu dan Teknologi Hayat. Bandung.

Rainkow, D. R. P. Landrum and $\mathrm{H}$. Vanderploeg. 2005. Invertebrate Resting Eggs as Secondary Aquatic Invsion Vector. http:// www.google.com. 7/Maret/2008. 8 hal.

Rojas, N.E.T., M. A. Marins and O. Rocha. 2000. The Effect of Abiotic Factors on the Hatching of Moina michura Kurz, 1984 (Crustacea: Cladocera) Ephippial Eggs. Braz. J. Biol. 61(3). Sao Carlos. 15 hal.

Sayuti. 2003. Budidaya Koki Pengalaman dari Tulung Agung. Agromedia Pustaka. Jakarta. hal. 70-73.

Setyowati, C. 2007. Pengaruh Kombinasi Intensitas Cahaya dan Lama Penyinaran terhadap Efektifitas Penetasan Ephipia Daphnia sp.. Skripsi. Program Studi S-1 Budidaya Perairan. Fakultas Kedokteran Hewan. Universitas Airlangga. Surabaya. 52 hal.

Simpson, G. 2001. Life History of Cladocera. www.homepages.ucl. 3/ Juli/ 2007. 1 pp.

Vandekerhove, J. S. Declerek, L. Brendonck, J. M. Condeporcuna, E. Jeppsen and L. 
D. Meester. 2005. Hatching of Cladoceran Resting Eggs: Temperature and Photoperiod. Journal of Feshwater Biology. 50 (1): 96-112.
Ward, J. V. 1992. Aquatic Insect Ecology 1. Biology and Habitat. John Willey and Sons, Inc. New York. Hal. 201355. 